\title{
Offsite Construction: Strategic Priorities for Shaping the Future Research Agenda
}

\author{
Jack Goulding $^{1}$, Farzad Pour Rahimian ${ }^{2}$, Mohammed Arif ${ }^{3}$, and Mark Sharp ${ }^{4}$ \\ ${ }^{1}$ Professor of Construction Project Management, School of Built and Natural Environment, University of Central \\ Lancashire, Preston, PR 1 2HE, UK; Email: jsgoulding@uclan.ac.uk \\ ${ }^{2}$ Senior Lecturer, Faculty of Design and Architecture, Universiti Putra Malaysia, Serdang, 43300, Malaysia \\ ${ }^{3}$ Senior Lecturer, School of Built Environment, University of Salford, Maxwell Bldg., The Crescent, Greater \\ Manchester, M5 4WT, UK \\ ${ }^{4}$ Chief Executive, Association of International Property Professionals, St Clements House, 27-28 Clements Lane, \\ London EC4N 7AE
}

doi:10.5618/arch.2012.v1.n1.7 || Received: 27-02-2012, Accepted: 11-04-2012, Available online: 15-04-2012

\begin{abstract}
Modern Methods of Construction (MMC), Offsite Manufacturing (OSM), and Offsite Production (OSP) are all umbrella terms cited as being possible panacea solutions for addressing time, quality and cost concerns often associated with 'traditional' construction. In this respect, these issues have been on the agenda for a while now, with no viable business process models or solutions [cf. traditional to manufacturing/installation] being proffered or promoted as a meaningful ways forward. In an attempt to address this, a focus group workshop was established with domain experts to explore industry uptake and multidisciplinary expectations and priorities within the AEC sector. This paper presents findings from this session, covering the relationships between people, process and technology - mapped against the three core silos of Design, Manufacturing and Construction. Research areas investigated embraced several integral issues, from information and process flows, through to production, risk, and market drivers and inhibitors. Research findings identified a high demand for technology adoption in the design and construction remits, and a need to change traditional thinking across the whole supply chain. Core findings and priorities are presented for industry reflection in order to shape the future research agenda in this area.
\end{abstract}

Keywords: Modern Methods of Construction; Offsite Manufacturing; People, Process; Technology; Industry Uptake.

\section{Introduction}

Manufactured construction, off-site construction, off-site manufacturing, industrialised building systems and modern methods of construction are some generic terms that have been used interchangeably in extant literature to describe pre-fabricated construction; where the intent of which is to move some of the construction effort into controlled environments within manufacturing facilities [1]. Given this, offsite construction can provide such specific benefits, as higher speed of construction, enhanced quality outputs, higher tolerances, lower costs, and reduced labour re-works on-site [2].

From a global perspective, Governments worldwide have promoted offsite construction for many years. For example, Japan is world's largest practitioner of manufactured construction, with companies such as Sekisui Homes producing 70,000 manufactured homes a year [3]. Other exemplars include the establishment of the Manufactured Home Construction and Safety Standards Act in the United States of America (USA) in 1976 (42 U.S.C. Sections 5401-5426), also referred to as the Housing and Urban Development (HUD) Code, which was designed to regulate the construction of manufactured homes. These federal standards regulate manufactured housing design and construction, including strength and durability, transportability, fire resistance, and energy efficiency. Other initiatives include the United Kingdom (UK), where the government identified manufactured construction as a key tenet for improving construction in the 21 st century, and was included the Egan's [4] report titled Rethinking Construction. In addition, the Industrialised Building System (IBS) in the UK is currently around 2\% (£2-3bn pa) of the country's total construction market, and is 
mainly run by fairly small companies [5]. Taylor [6] relates this failure to inaccurate public assumptions of the IBS, advocating that the implementation of IBS could benefit the society in several ways. Arif et al. [7] also highlighted IBS misconceptions, noting that consensus was needed in order to promote and leverage synergy through processes and systems. Similarly, the Australian construction industry has likewise identified manufactured construction as a key vision for improving the industry over the next decade [8]. Similarly, countries like Malaysia have legislation requiring the use of offsite in construction projects [9]. These reports and initiatives all highlight the importance of MMC, OSM and OSP, given that some findings have suggested that the use of offsite techniques can result in 16\% lower labour and material costs [10].

However, despite all these espoused benefits and global initiatives, the uptake of offsite manufacturing is much slower than expected, with its market share in UK construction being reported to be below 6\% [5]; and in the USA there are approximately 7 million occupied manufactured homes, which make up about $7 \%$ of the nation's housing stock [11]. As an example, in the UK, the construction industry contributes to $8 \%$ of the country's Gross Domestic Product (GDP) with over 201,100 enterprises, and an annual turnover of $£ 152 \mathrm{bn}$, and approximately 1.4 million employees [12]. This GDP breakdown is broadly proportional to other countries over the world. Therefore, given this prominence and importance, literature has advocated the increased need to employ cutting-edge technologies [13] to address the emerging challenges introduced by the global Architecture/Engineering/Construction (AEC) projects $[14,15]$. On an tangential issue, it is important to note here that information and communication technology (ICT) has revolutionised production and design [16]. This has led to dramatic changes in terms of production materials and labour [17]; and the increased use of ICT tools within design and construction now enables designers to experiment and experience OSM decisions in a 'cyber-safe' environment in order to mitigate or reduce risks prior to construction $[18,19]$.

The rapid growth of technology adoption and absorption has been widely evidenced in several other industries. However, the same cannot be said for the construction industry, especially regarding on-site and off-site information flow, materials and labour management [20]. However, there are some promising emerging ICT enabled approaches, e.g. Building Information Modelling (BIM), which could support a comprehensive digital representation of all construction information for various stages of the project lifecycle
[21]. Moreover, BIM adoption could also enhance team collaboration [21], project integration [22], construction information flow [23], documentation [24], and teamwork planning and coordination [25]. Given these developments in ICT and opportunities arising out of OSM, Taylor [6] asserted that an industrialised system of construction could provide "affordable quality homes" and overcome some of the major problems inherent with the traditional approach to construction. Therefore, if offsite production and manufacture is to make a positive contribution to all societal stakeholders, additional research is needed to identify the main preventative barriers to its uptake and adoption, including such issues as culture, demand-supply production and business models, socio-economic drivers etc. Against this background, a 'representative' Task Group was established to evaluate and prioritise these issues in order to establish a cogent research agenda for future uptake.

\section{Methodology}

This study specifically focuses on the socio-politicaltechnical relationships that affect the uptake and adoption of OSM. It adopted an interpretive approach to positioning, as it sought to uncover new meanings and constructs. The research methodological approach adopted used a mixed-method research design, which included a series of discursive on-line interviews with domain experts to collect primary data. These findings were then presented in a formal workshop, where the results were explored in depth. Initially, the causal problems and key issues that impinged upon the successful uptake of OSM were identified through extant literature over the last 20 years. The temporal timeframe reflects relevance and proximity, and the research lens was open-bounded, thereby not constrained by context, regional or geographical issues. From this, three areas of concern (Process, Technology, People) cutting across three sectors (Design, Manufacturing, Construction) were identified as the main units of analysis. The data was analysed using SPSS, and the One-Way ANOVA test was used to determine significance and correlation.

In terms of the methodological approach, this stage followed guidelines for collecting data through focusgroup-workshops. Prior to conducting the workshop, the issues of the study were clearly articulated and the questions predetermined [26] according to the objectives of the research. This method is often characterised with its clear use of group communication to generate data and thoughts that would not be easily accessible via the ordinary individual interviews [27], hence can be 
considered efficient for generating ideas regarding new products and phenomena based on the experts' commonality [28].

\section{Workshop results}

In order to reveal the current state and multidisciplinary expectations towards technology adoption within the construction industry, the workshop investigated the current needs and challenges in terms of the three core industry sectors (Process, Technology, People). In addition, each indicator was examined with respect to all three major aspects of the industry (Design, Manufacturing, Construction). Given these boundaries, the workshop investigated the relationships between the first group of variables (i.e. Process, Technology, People) and the second group of variables (i.e. Design, Manufacturing, Construction). Consequently, the main objectives of this workshop was to identify the key needs of the industry with regard to the nine core issues as follows: 1) technology-design, 2) technologyconstruction, 3) technology-manufacturing, 4) processdesign, 5) process-construction, 6) process-manufacturing, 7) people-design, 8) people-construction, and 9) people-manufacturing. These areas can be seen in Figure 1.

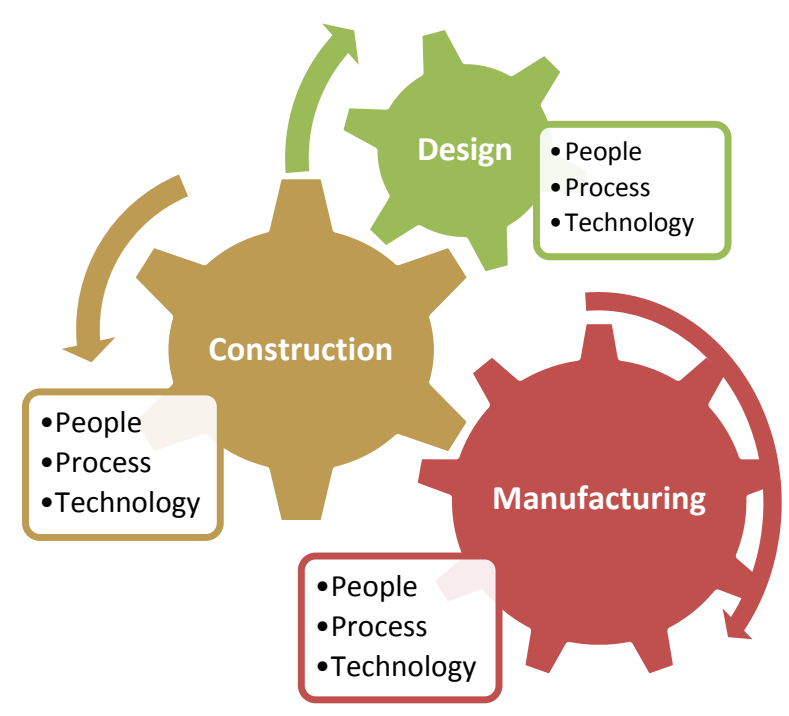

Fig. 1.: Core Issues Identified

3.1 Organisation of the Focus Group Workshop. The workshop was conducted in the UK, attracting 18 international participants from academia and industry.
Based on the background knowledge and expertise of the participants, they were divided into two discussion groups, supported by a discussion moderator in each group. The workshop was divided into four sessions, namely introduction, individual survey, within-group discussions, and between-groups discussion. At the outset of the workshop the participants were provided with an overview of the nine objectives of the workshop. Afterwards, a perception survey was conducted through a structured questionnaire comprising of 27 questions regarding the aforementioned nine objectives of the workshop. The questionnaire was a result of the preceding online workshops, which garnered ideas and concepts from international scholars within the field. The workshop then continued to within-group discussions and was concluded with a between-group discussion. All questionnaires were collated and transcribed for data analysis purposes.

3.2 Importance of developments in issues related to technology, process, and people. This research adopted a mixed-method data collection process, comprising of a quantitative structured questionnaire survey methodology and qualitative group discussions. The analysis relied on findings from both qualitative and quantitative methods. In other words, this forum extracted explicit results through the conducted survey, and then validated them via triangulation [26] with the transcribed results of the group discussions.

For analysing the findings regarding technology, process, and people with respect to three aspects of the offsite construction (i.e., design, manufacturing, and construction), this study adopted both in-between and within groups analysis strategies. From initial analysis, it holistically compared the level of the participants' responses and considerations regarding technology, process, and people issues. As shown in Figure 2, in terms of top level analysis, this study compared each participant's perception towards the importance of developments in the UK's building industry in issues related to technology, process, and people. The results showed that the participants strongly supported the developments in all three areas (with more than 70\% importance).

However, the One-Way ANOVA test conducted revealed that there was no significant difference between people, process and technology $(\mathrm{F}=1.836$, $\mathrm{df}=145$, and $\mathrm{p}>.05$ ) and that participants considered the importance of the development in the three areas to be equal. The following sections elaborate on the withingroup relationships of aforementioned three groups. 


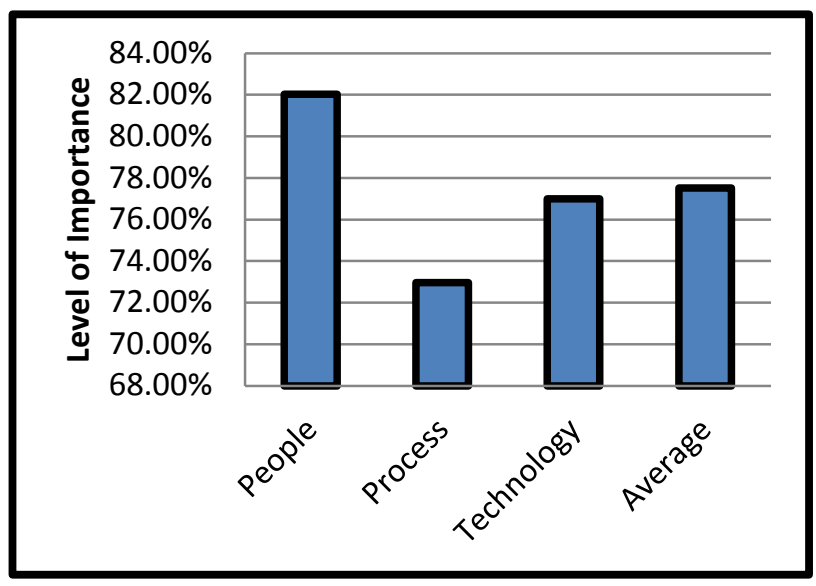

Figure 2. Importance of developments in issues related to technology, process, and people

The study also investigated the participants' perception towards people, process and technology in all the three areas of offsite construction: design, manufacturing and construction. Figure 3 summarises the responses as far as the need for research in the identified nine areas. Figure 3 identifies that there was a similarity in the distribution patterns for the requested developments in human resources, the existing processes, and the existing technology. In contrast, Figure 3 identified that although there are similar importance assigned by the participants for enhancements in design and construction areas, the importance assigned to manufac- turing is significantly lower. Figure 3 illustrates that the need for improvements in manufacturing is significantly lower than construction and design. This also demonstrates that within manufacturing there is a higher need for improvements in people related issues compared to technology and processes. Nevertheless, this study presents several inferential statistical analyses for further elaboration of the facts associated with the collected data.

3.3 Developments in Human Resources. In terms of the issues related to people, Figure $\mathbf{3}$ shows that there was a high need as identified by responses from the survey for new developments in all identified three areas of the offsite construction sector, namely: design, manufacturing, and construction. The conducted ANOVA test also indicates that there was no statistically significant difference between need for further developments and research in design, manufacturing, and construction areas $(\mathrm{F}=2.861, \mathrm{df}=50$, and $\mathrm{p}>.05)$.

As shown in Table 1, considerations regarding the timeframe for developments significantly varies regarding design, manufacturing, and construction $(\mathrm{F}=5.585, \mathrm{df}=111$, and $\mathrm{p}<.001)$. In other words (based on the results of the conducted Post-Hoc test), although participants advocated that people related developments urgently need to improve the competence of the current design teams (within 0-5 years), they considered the development of construction and manufacturing to fall within a longer period of time (6-10 years).

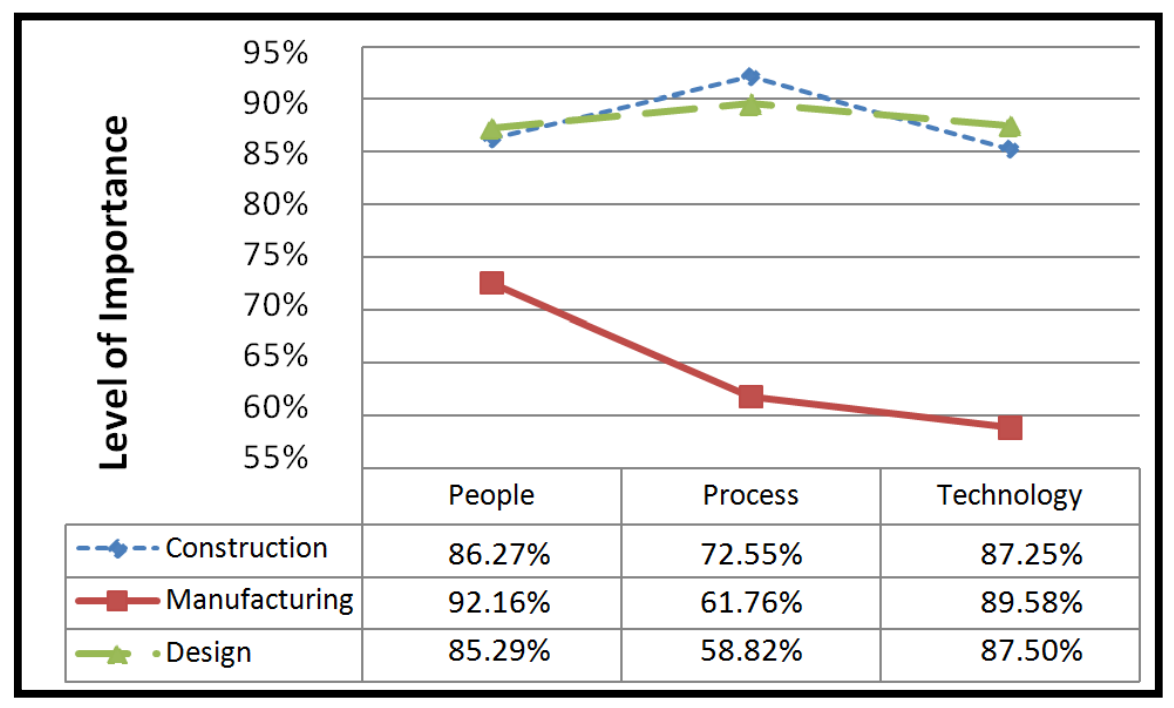

Figure 3. Degrees of demand for enhancements in the nine different areas of the study 
Table 1. ANOVA test result for comparing considerations regarding the timeframe of developments of people in areas of design, manufacturing, and construction

\begin{tabular}{|c|c|c|c|c|c|c|}
\hline (I) Development Area & $\mathrm{N}$ & Mean & $\begin{array}{l}\text { Std. } \\
\text { Dev. }\end{array}$ & $\begin{array}{l}\text { (J) Development } \\
\text { Area }\end{array}$ & $\begin{array}{l}\text { Mean Difference } \\
(\mathrm{D}=\mathrm{J}-\mathrm{I})\end{array}$ & Sig. \\
\hline \multirow[t]{2}{*}{ Construction } & 38 & 1.55 & 0.65 & Design & 0.32 & 0.06 \\
\hline & & & & Manufacturing & -0.14 & 0.57 \\
\hline \multirow[t]{2}{*}{ Design } & 38 & 1.24 & 0.49 & Construction & -0.32 & 0.06 \\
\hline & & & & Manufacturing & $-0.46(* * *)$ & 0.00 \\
\hline \multirow[t]{2}{*}{ Manufacturing } & 36 & 1.69 & 0.67 & Construction & 0.14 & 0.57 \\
\hline & & & & Design & $0.46(* * *)$ & 0.00 \\
\hline Total & 112 & 1.49 & 0.63 & Among groups & $\begin{array}{l}\mathrm{f}=5.585(* * *) \\
\mathrm{df}=111\end{array}$ & 0.00 \\
\hline
\end{tabular}

${ }^{*} \mathrm{p}<.05$ (Significant Difference), $* * \mathrm{p}<.01$ (Very Significant Difference), $* * * \mathrm{p}<.001$ (Absolutely Significant Difference)

$1<$ Mean $<1.5$ (Short-term Development); $1.5<$ Mean $<2$ (Medium term Development); $2<$ Mean $<3$ (Long-term Development)

In terms of Design-People developments, both groups were of the opinion that there was a need to re-train Architects and Designers to maximise benefits. For example, training in Design for X (DFX) and Design for Manufacture (DfM) approaches can offer new ways and insights not normally captured through traditional methods. This could help achieve component standardisation and reduce design variability, which would make manufacturers' business models more viable, whilst offering greater flexibility to constructors. This new thinking also mirrors the traditional architectural philosophy that "form follows functionality"; which is now truer than ever, especially as functionality also includes manufacturability and constructability (and not just functionality post-occupancy of the building). This area was therefore rated as high priority. In addition, the results presented in Figure 4 indicated equally $(\mathrm{F}=0.358, \mathrm{df}=37$, and p>.05) urgent needs (within 0-5 years) for new skills (Mean Var1= 1.21), new approaches to design (Mean Var2 $=1.33$ ), and design for manufacture and assembly (importance, along with logistic integration into the design process) (Mean Var3 $=1.17$ ).

In this study employing new skills meant developing competence for applying new ways of working (e.g. product modelling), new way of design thinking, and changing individual/company behaviour. The study also considered the need for new approach to design as the key Unique Selling Points (USPs) that need to be sold to suppliers, assemblers, transport operations etc.

With regards to Construction-People issues, the participants asserted that one of the key benefits of manufactured construction was the potential to reduce site waste. Given the current emphasis on sustainability, it was therefore deemed important that construction personnel were made aware of these benefits. This however, would require re-training and re-skilling of operatives in the practices of manufactured construction in order to harness the benefits of waste reduction. Further positive impacts were also acknowledged if manufacturing schedules were linked to actual construction processes, so that storage and double handling could be minimised. Therefore, greater manufacturing awareness would be a natural part of this up-skilling and re-training, so that processes are holistically managed to leverage potential benefits. This area was therefore rated as high priority.

In terms of timeframe of proposed different changes in this area, results presented in Figure 4 indicated equal importance $(\mathrm{F}=1.479, \mathrm{df}=32$, and $\mathrm{p}>.05)$, and was assigned a medium-term timeframe (within 6-10 years) for up-skilling of construction personnel (onsite and offsite) (Mean Var1 = 1.31), enhancing healthy/ comfortable working conditions (e.g. new USP, improved health and safety, better working conditions, overcome age/gender barrier etc) (Mean Var2 $=1.69$ ), and promoting sustainability issues (social, environmental, carbon emissions etc) (Mean Var3 = 1.67). 


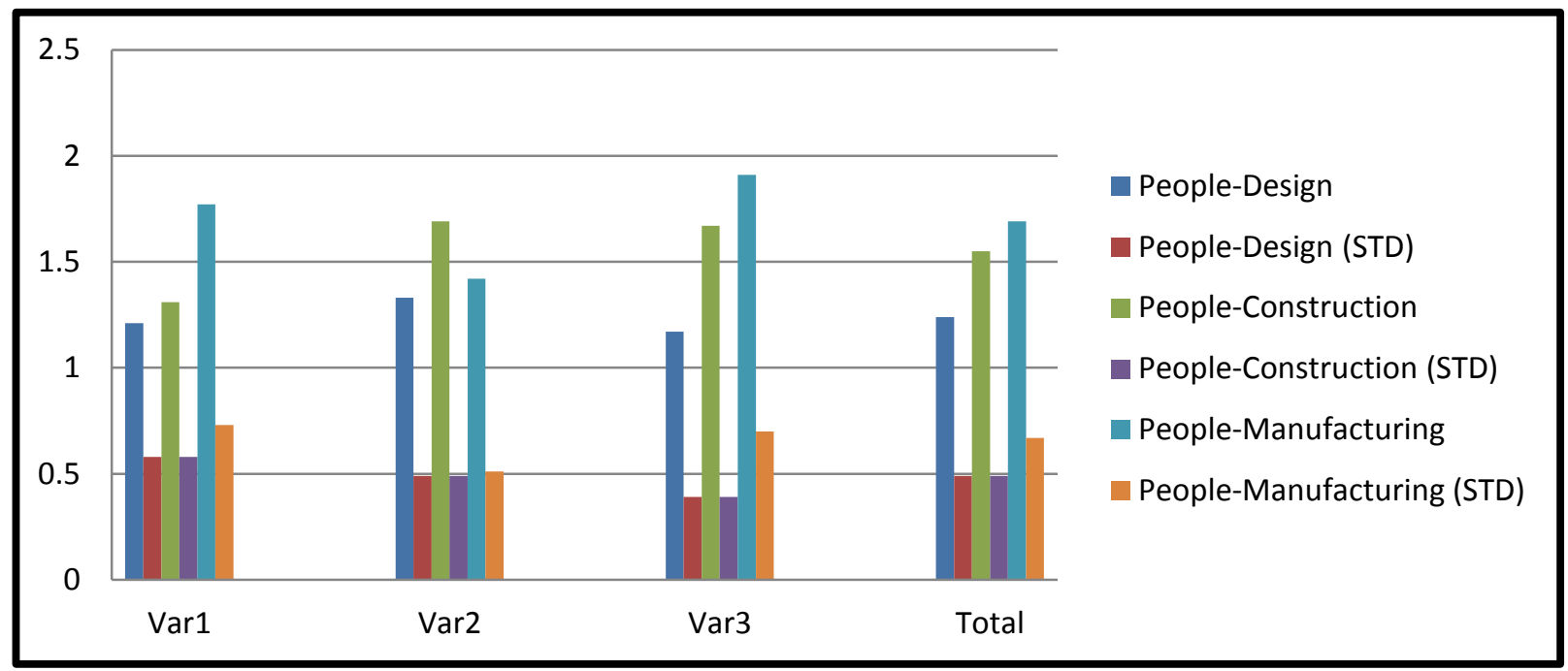

Figure 4. Considerations regarding the timeframe of developments of people area

Finally, with regards to Manufacturing-People issues, it was generally accepted that personnel within the manufacturing sector were familiar with both masscustomisation as well as bespoke one-job scenarios. Therefore, embracing variations to meet new sectoral requirements imposed by the demands of offsite construction environment would not pose a major challenge. The workforce could adopt bespoke or mass production scenarios, along with demand.

However, it was noted that processes and practices of manufacturing would need to be communicated differently to construction and design in order for design and construction personnel to liaise more effectively with manufacturing personnel. For example, coordination is particularly important with not just the design team, but also with the construction team, as there is an important need to ensure that construction site and construction approaches are dovetailed to meet the manufactured components and logistics rollout schedules. This area was assigned a low to medium level priority. In other words, the results (shown in Figure 4) revealed equal importance $(\mathrm{F}=1.76, \mathrm{df}=35$, and $\mathrm{p}>.05)$ assigned to understanding the impact and effectiveness of training (mind-set change: look at projects rather than products) (Mean Var1 $=1.77$ ), manufacturing decisions to be modelled in an integrated way (incorporating risks and changing shop floor approach) (Mean Var2 = 1.42), and improvements in mass customisation-service parts (to address the markets) with alignment to job roles and functions (integrating people into the model) (Mean $\operatorname{Var} 3=1.91)$ and all three of them assigned a medium term timeframe (within 6-10 years).

3.4 Developments in Process. With respect to the needs for enhancements in the process, Figure 3 shows a highly fluctuating demand level for developments in the identified three areas of the industry, namely: design, manufacturing, and construction. This analysis revealed that although the participants asserted that the improvement in the existing process of design and construction are crucial (almost 90\% important), they recognised a moderate $(61.76 \%)$ importance for the improvements in the process of the related manufacturing systems. Ultimately, the conducted ANOVA (presented in

Table 2) test proved that the aforemen- tioned difference is highly significant $(\mathrm{F}=12.01, \mathrm{df}=49$, and $\mathrm{p}<.001)$.

However, the conducted ANOVA test revealed that results regarding the timeframe for the developments in process did not significantly vary regarding design, manufacturing, and construction $(\mathrm{F}=1.71, \mathrm{df}=107$, and $\mathrm{p}>.05)$ and the respondents asserted that the enhancement in all three fields should be applied within a short period of time (0-5 years). 
Table 2. ANOVA test result for comparing demands for improvements of process in areas of design, manufacturing, and construction

\begin{tabular}{|c|c|c|c|c|c|c|}
\hline (I) Development Area & $\mathrm{N}$ & Mean & $\begin{array}{l}\text { Std. } \\
\text { Dev. }\end{array}$ & $\begin{array}{l}\text { (J) Development } \\
\text { Area }\end{array}$ & $\begin{array}{l}\text { Mean Difference } \\
(\mathrm{D}=\mathrm{J}-\mathrm{I})\end{array}$ & Sig. \\
\hline \multirow[t]{2}{*}{ Construction } & \multirow[t]{2}{*}{17} & \multirow[t]{2}{*}{$92.16 \%$} & \multirow[t]{2}{*}{0.40} & Design & $2.57 \%$ & 0.93 \\
\hline & & & & Manufacturing & $30.39 \%(* * *)$ & 0.00 \\
\hline \multirow[t]{2}{*}{ Design } & \multirow[t]{2}{*}{16} & \multirow[t]{2}{*}{$89.58 \%$} & \multirow[t]{2}{*}{0.48} & Construction & $-2.57 \%$ & 0.93 \\
\hline & & & & Manufacturing & $27.82 \%(* * *)$ & 0.00 \\
\hline \multirow[t]{2}{*}{ Manufacturing } & \multirow[t]{2}{*}{17} & \multirow[t]{2}{*}{$61.76 \%$} & \multirow[t]{2}{*}{0.82} & Construction & $-30.39 \%(* * *)$ & 0.00 \\
\hline & & & & Design & $-27.82 \%(* * *)$ & 0.00 \\
\hline Total & 50 & $81.17 \%$ & 0.72 & Among groups & $\begin{array}{l}\mathrm{f}=12.01(* * *) \\
\mathrm{df}=49\end{array}$ & 0.00 \\
\hline
\end{tabular}

With regards to Design-Process, developments in this area were identified as being critical, as core processes under the umbrella term of Design for $\mathrm{X}$, which incorporates philosophies such as Design for Manufacture and assembly, design for constructability and design for sustainability etc. It was therefore felt that this should be promoted; but, in order to add value to the overall construction/production process, it was important to acknowledge the 'value' added by different members of the supply chain. Therefore, these values could be incorporated at the design phase itself and the overall success of the project could then be decided upon based on the achievement of these values. Given the involvement of more parties in manufactured construction compared to traditional construction, it was therefore perceived important that all the stakeholders be involved in the project right from the design phase itself. In addition, more effective implementation of concurrent engineering practices could be engaged to facilitate the effective design process. This area was therefore rated as high priority. However, as presented in Figure 5, the study found a significant differences of opinions among respondents' idea regarding timeframe of different changes $(\mathrm{F}=3.93, \mathrm{df}=34$, and $\mathrm{p}<.05)$. Based on the results of the conducted survey, the participants asserted that there are urgent needs (within 0-5 years) for defining and adding value to the business processes
(Var1) and understanding the impact of design and process on business and technology (Var3). However, the results showed that the participants supported the use of process protocol for lifecycle process analysis (including stakeholder analysis and the impact on them) (Var2) within a longer period of time (6-10 years).

In terms of Construction-Process, it was noted that process in manufactured construction could be reduced to replicate an assembly process. However, this was a very different way of putting together a building, where large components and modules are assembled like Lego blocks. The traditional construction process often requires component connection and assembly on site rather than through pre-assembly often engaged on the manufacturing floor. Therefore, what is needed is a complete re-think of the construction philosophy, processes, and practices. In this respect, construction professionals need to be re-trained to think differently in order to approach a project with a new mindset, which synchronises processes and activities with the manufacturing and design team from a very early stage. This category was therefore rated high, as the consequence of this transcends the traditional construction vs. manufactured construction process conundrum. Furthermore, as presented in Figure 5, the participants proposed equally $(\mathrm{F}=0.56, \mathrm{df}=37$, and $\mathrm{p}>.05)$ 
urgent actions (within 0-5 years) for integrating construction with process (e.g. through RFID, BIM, IPPD, etc) (Var1), understanding the interface between OSP and manufacturing (Var2), and enhancing flexibility (vis-à-vis elements of standardisation, economics of scale etc) (Var3).

Finally, regarding the developments in Manufacturing-Process, the participants recognised the importance of the issue and asserted that manufacturing can be very effective in mass production scenarios; but, given the bespoke nature of the construction industry, a completely different manufacturing paradigm is needed which overtly incorporates design flexibility. It is therefore imperative that the manufacturing processes start providing inputs right at the beginning of the design process. Conversely however, the manufacturing processes need to be more flexible in order to accommodate design changes, engaging a system traditionally referred to as "job-shop" scenario in manufacturing literature. To maximise this, a streamlined value-based manufacturing process is needed to derive the maximum benefits out of manufactured construction. This area was also rated high by all participants.

However, as presented in Figure 5, they proposed equally $(\mathrm{F}=1.35, \mathrm{df}=34$, and $\mathrm{p}>.05)$ medium term timeframes (within 6-10 years) for: 1) defining new procedures and variables considering other industries (not just efficiency over productivity) (Mean Var1= 1.33 ), 2) creating new business models (Mean Var2= 1.67), and 3) understanding the breakeven point for automation vs. non-automation (Mean Var3= 1.82).

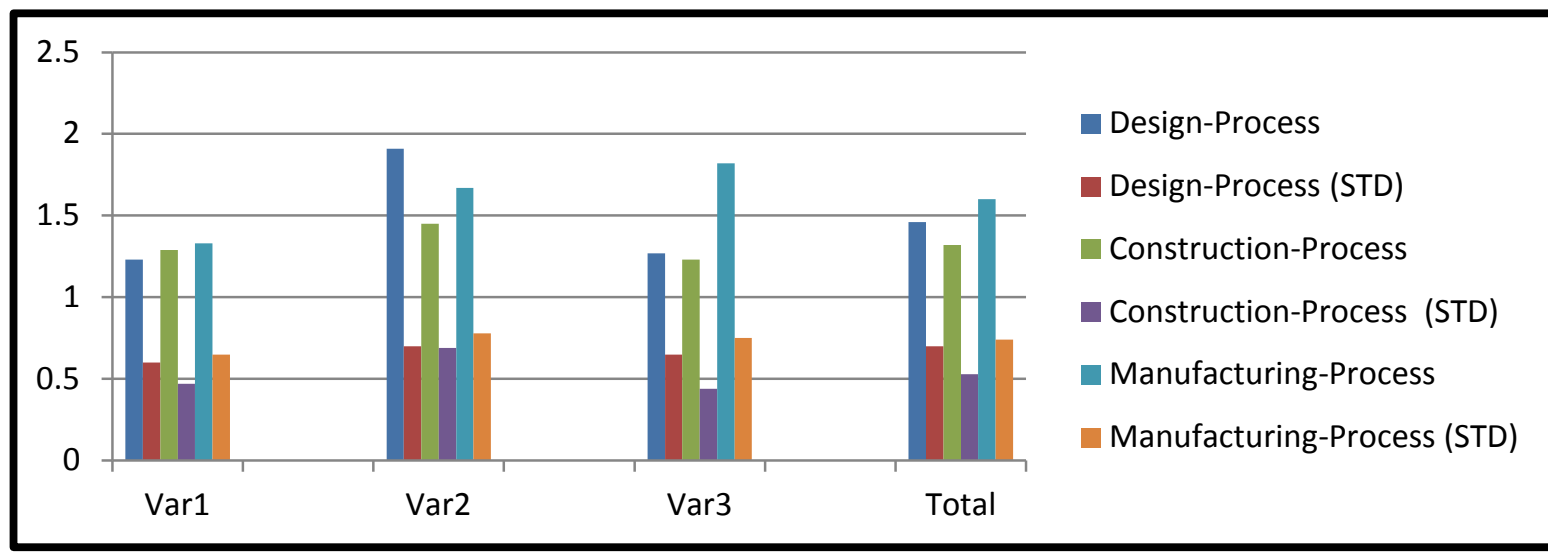

Figure 5. Considerations regarding the timeframe of developments of people area.

3.5 Developments in Technology. In terms of the needs for technological advancements, the responses differed significantly for the design, manufacturing and construction, as shown in Figure 3. This shows that the technological advancements in design and construction systems are crucial for the respondents (more than $85 \%$ of importance), whilst respondents recognised a very moderate $(58.82 \%)$ importance for the technological developments of the respective manufacturing systems. The ANOVA test reported in Table 3 revealed that the differences are highly significant $(\mathrm{F}=12.69, \mathrm{df}=49$, and $\mathrm{p}<.001)$.

However, based on the conducted ANOVA test, the considerations regarding the timeframe for the technological advancements did not significantly vary regarding design, manufacturing, and construction $(\mathrm{F}=$ $2.57, \mathrm{df}=103$, and $\mathrm{p}>.05$ ) and the respondents asserted that the enhancement in all three fields should be applied within a medium term timeframe (6-10 years).

With respect to the technological advancements in design systems, both groups were of the view that this was an important area. However, in order for organisations to implement this effectively they needed to have a good understanding on the design process. Whilst Building Information Modelling (BIM) has been gaining popularity in the last decade, there was acknowledgement that to effectively implement BIM, it was also important to establish appropriate processes, communication links, hardware and software structures, and suitably-trained people to use these new technologies. Therefore, only after meeting all these pre-requisites could effective design technology implementation occur. Participants did however feel that given the current emphasis on sustainability and the 
ability to simulate different design parameters using design technology, this factor should be at least given a medium priority in the short to medium term. Ultimately, in terms of timeframe for changes, data presented in Figure 6 revealed equally $(\mathrm{F}=0.02, \mathrm{df}=32$, and $\mathrm{p}>.05)$ medium term needs (within 6-10 years) for improving design of products made in the factory (Var1), underpinning the business process to benefit all supply chain partners (Var2), and BIM adoption to support offsite products and processes (Var3).

Improvements in Construction-Technology were perceived to be critical to the development and progress of the area of manufactured construction. Effective interaction with manufacturing and design, and technologies that facilitate this interaction, along with providing deeper insights into the implications of decisions were deemed pivotal. It was noted that there needed to be an effective mechanism in place that could assess the risks associated with use of new construction technology and its interaction with manufacturing and design. Given the importance that construction technology has in the overall success of manufactured construction, this was therefore rated as high priority. In this respect, it was felt that more research was needed in this area to identify the variables that could have an impact on the effective implementation of construction technology. However, there was a significant difference among the proposed timeframes for adopting different changes $(\mathrm{F}=3.33, \mathrm{df}=37$, and $\mathrm{p}<.05)$ in issues related to Construction-Technology. Based on the results presented in Figure 6, the participants asserted that there are urgent needs (within 0-5) to clearly understand the future's respective information flow systems (e.g. Product Modelling Ontology, W3C etc) (Var1) and identify the methods in which the technology can support the existing products, processes, and application (Var2). However, the results also revealed that the participants proposed the allocation of a longer time (6-10 years) to better indentify the potential risks of applying the new systems (Var3).

Finally, based on the analysis of the results regarding Manufacturing-Technology, both groups felt that building houses was different from building cars, given their bespoke nature. It was therefore quite reasonable to automate production lines as several millions of same model cars could be manufactured. However, when it comes to manufacturing buildings or houses, there needs to be inherent flexibility built in to accommodate bespoke design variances.

Table 3. ANOVA test result for comparing demands for improvements of technology in areas of design, manufacturing, and construction.

\begin{tabular}{|c|c|c|c|c|c|c|}
\hline (I) Development Area & $\mathrm{N}$ & Mean & $\begin{array}{l}\text { Std. } \\
\text { Dev. }\end{array}$ & $\begin{array}{l}\text { (J) Development } \\
\text { Area }\end{array}$ & $\begin{array}{l}\text { Mean Difference } \\
(\mathrm{D}=\mathrm{J}-\mathrm{I})\end{array}$ & Sig. \\
\hline \multirow[t]{2}{*}{ Construction } & 17 & $85.29 \%$ & 0.43 & Design & $-2.21 \%$ & 0.94 \\
\hline & & & & Manufacturing & $26.47 \%$ & 0.00 \\
\hline \multirow[t]{2}{*}{ Design } & 16 & $87.50 \%$ & 0.39 & Construction & $2.21 \%$ & 0.94 \\
\hline & & & & Manufacturing & $28.68 \%$ & 0.00 \\
\hline \multirow[t]{2}{*}{ Manufacturing } & 17 & $58.82 \%$ & 0.75 & Construction & $-26.47 \%$ & 0.00 \\
\hline & & & & Design & $-28.68 \%$ & 0.00 \\
\hline Total & 50 & $77.00 \%$ & 0.67 & Among groups & $\begin{array}{l}\mathrm{f}=12.69(* * *) \\
\mathrm{df}=49\end{array}$ & 0.00 \\
\hline
\end{tabular}

${ }^{*} p<.05$ (Significant Difference), ${ }^{* *} p<.01$ (Very Significant Difference), ${ }^{* * *} p<.001$ (Absolutely Significant

Difference) 


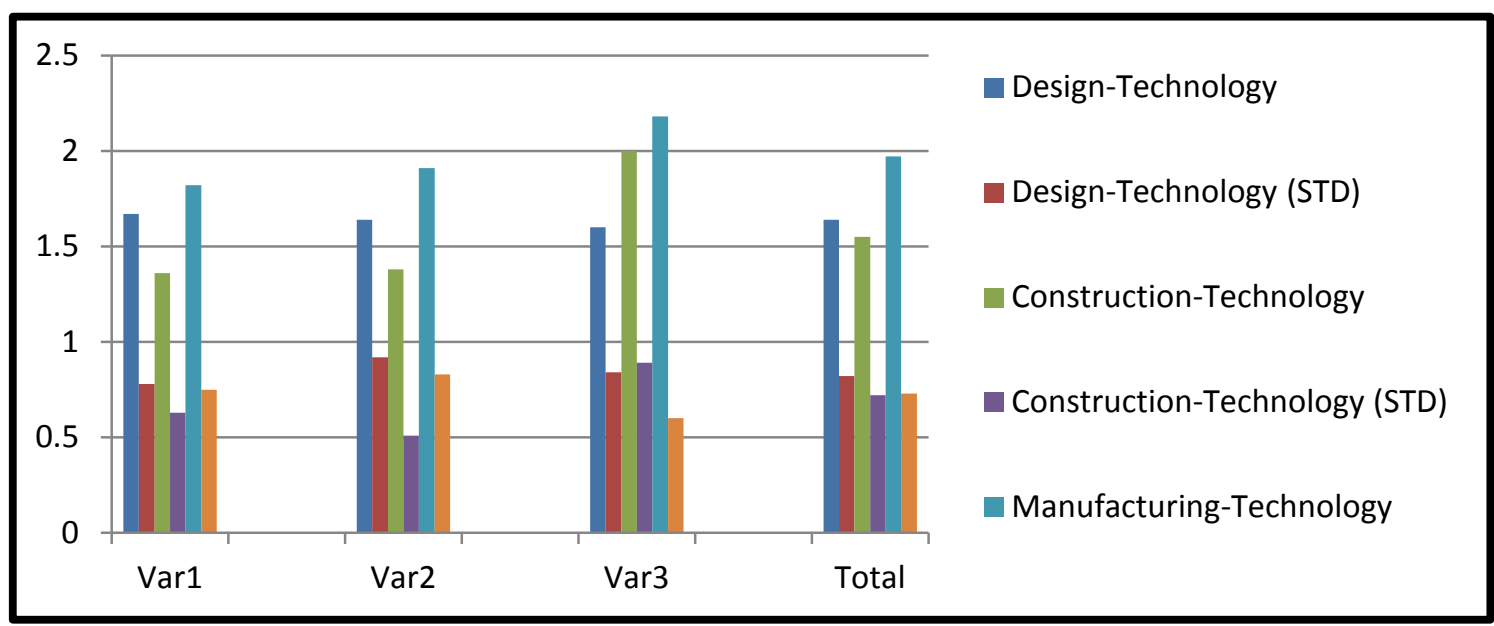

Figure 6. Considerations regarding the timeframe of developments of people area.

Therefore, a high level of automation seemed infeasible for manufactured construction; but, a 'justifiable' level of automation or mechanisation could be implemented. Therefore, as presented in Figure 6, the groups felt that this should be recorded as low priority in equally $(\mathrm{F}=0.73, \mathrm{df}=32$, and $\mathrm{p}>.05)$ medium-term (6-10 years) for all three proposed advancements in manufacturing systems: 1) automation and optimisation of the manufacturing and payback systems (Var1), 2) development of business cases, employing new software applications (DFM, systems development, Decision Support Systems, integrated product delivery, Materials Requirement Planning and Enterprise Resource Planning etc) for enhancing operations and decisions (Var2), 3) and developing software analysis tools such as systems analysis, discreet event simulation and modelling etc (Var3).

\section{Conclusion}

One of the key deliverables of this Task Group was to encompass prioritised areas for offsite production and manufacturing. This paper presents the development of guidelines for the short-term (0-5 years) and medium-term (6-10 years) timeframes. Beyond this 10 year timeframe was considered unfeasible due to the dynamism of the market and changing socio-political landscape. Research data was divided into three areas (people drivers, process drivers and technology drivers), and ranked accordingly. In the People Drivers, addressing issues relating to training design professionals to deal with offsite was identified as high priority, and this area was identified as important in the short-term. The development of skills for construction was rated as medium priority and important in the medium-term timeframe; and the area of manufacturing people was rated lowest among the people-related drivers (categorised with a medium-term timeframe). Among the Process Drivers, construction process was regarded as high priority in the short-term, with design process classed as medium priority in the 0-5 year timeframe, followed by manufacturing process (low priority in the medium-term timeframe). Among the Technology Drivers, construction-related technology was consider high, with design-related technology was medium, and manufacturing-related technology was considered low in priority (all of which need to be addressed in the medium-term timeframe).

From this study, it is apparent that manufacturing has been recognised as being low priority in all three-driver categories. One possible reason for this may be that manufacturing per se, has matured significantly more than construction when it comes to the adoption of technology and the maturity of associated processes. In addition, whilst it is recognised that automation can be overtly observed within manufacturing; there is however an assumption that the construction sector industry could quite easily 'adopt' manufacturing without reinventing the wheel (which may have contributed to this rating). Acknowledging this, the implications from this research advocate the need to further prioritise these issues, as from an epistemological perspective it is accepted that contextual positioning and regional/ country-specific conditions and constraints may exist with this limited data set. These can be considered as 
bounded variables, which may affect the generalisability and repeatability of these findings. Notwithstanding this, there is an exigent need to identify the pivotal value-laden activities and socio-cultural forces that govern adoption, diffusion and dissemination. Moreover, it is equally important to understand the governing market forces, drivers and inhibitors supplanted in both the developed and developing world, as these nuances are likely to have significant impact on the future research agenda.

\section{Notes and References}

[1] Arif, M. and C. Egbu, Making a Case for Offsite Construction in China. Engineering Construction and Architectural Management, 2010. 17(6).

[2] Mullens, M.A. and M. Arif, Structural Insulated Panel: Impact on the Residential Construction Process. Journal of Construction Engineering and Management (ASCE), 2006. 132 (7): p. 786-794.

[3] Gann, D.E., Construction as a manufacturing process? Similarities and differences between industrialized housing and car production in Japan. Construction Management and Economics, 1996. 14(1): p. 437-450.

[4] Egan, J., The Egan Report - Rethinking Construction, Report of the Construction Industry Taskforce to the Deputy Prime Minister,. 1998, London: HSMO.

[5] Taylor, M.D., A definition and valuation of the UK offsite construction sector. Construction Management and Economics, 2010. 28(8): p. 885-896.

[6] Taylor, S., Offsite Production in the UK Construction Industry, A Brief Overview. 2009, Construction Engineering Specialist Team: HSE: London. p. 30.

[7] Arif, M., C. Egbu, M. Alshawi, S. Srinivas, and M. Tariq, Promoting Green Construction in India through Industry-Academia Collaboration. JOURNAL OF PROFESSIONAL ISSUES IN ENGINEERING EDUCATION AND PRACTICE (C) ASCE 2010: p. 128-131.

[8] Hampson, K.D. and P. Brandon, Construction 2020 - A vision for Australia's Property and Construction Industry. 2004, Queensland University of Technology.

[9] CIDB, Industrialised Building Systems in Malaysia. 2006, CIDB Press.

[10] Schuler, A., The Factory Built Components Industry Is Almost As Large as the Softwood Lumber
Industry, in Structural Building Components Magazine. 2003.

[11] HAC, Preserving Affordable Manufactured Home Communities in Rural America: A Case Study. 2011, Housing Assistance Council Press.

[12] National Guidance Research Forum (N.G.R.F.). 2010 [cited 2010 14th Aug 2010]; Available from: http://www.guidance-research.org/future-trends/const ruction/info.

[13] Stewart, R.A., C. Miller, S. Mohamed, and G. Packham. Sustainable development of construction small and medium enterprises (SMEs): IT impediments focus. in W78 International Conference on Information Technology in Construction Construction IT Bridging the Distance. 2003. Auckland, New Zealand.

[14] Friedman, T.L., The World is Flat: A Brief History of the 21st Century. 2005, New York: Farrar, Straus and Giroux.

[15] Nadim, W. and J.S. Goulding, Offsite Production: A Model for Building Down Barriers: A European Construction Industry Perspective. Journal of Engineering, Construction and Architectural Management, 2010. 18(1): p. 82-101.

[16] Cera, C.D., W.C. Reagali, I. Braude, Y. Shapirstein, and C.Foster, a Collaborative 3D Environment for Authoring Design Semantics. Graphics in Advanced Computer-Aided Design, 2002. 22(3): p. 43-55.

[17] Fruchter, R., Internet-based Web Mediated Collaborative Design and Learning Environment, in Artificial Intelligence in Structural Engineering, in Lecture Notes in Artificial Intelligence. 1998, Heidelberg: Springer-Verlag: Berlin. p. 133-145.

[18] Goulding, J.S., M. Arif, and F. Pour Rahimian, New Production and Business Models in Construction: Priorities for the Future Research Agenda. Journal of Construction Engineering and Management (ASCE), 2011. Under Review.

[19] Petric, J., T. Maver, G. Conti, and G. Ucelli, Virtual reality in the service of user participation in architecture, in CIB W78 Conference. 2002: Aarhus School of Architecture.

[20] CII Research. Technology Needs Assessment. 2011 [cited 2011 08th Jan]; Available from: http://www.construction-institute.org/scriptcontent/17 $31 . \mathrm{cfm}$.

[21] $\mathrm{Gu}, \mathrm{N}$. and $\mathrm{K}$. London, Understanding and facilitating BIM adoption in the AEC industry. Automation in Construction, 2010. 19(8): p. 988-999. 
[22] Ibrahim, M., R. Krawczyk, and G. Schipporiet, Two Approaches to BIM: a Comparative Study, in Proceedings of eCAADe 2004. 2004.

[23] Woo, J.-H., M.J. Clayton, R.E. Johnson, B.E. Flores, and C. Ellis, Dynamic Knowledge Map: reusing experts' tacit knowledge in the AEC industry. Automation in Construction, 2004. 13(2): p. 203-207.

[24] Popov, V., S. Mikalauskas, D. Migilinskas, and P. Vainiunas, Complex Usage of $4 D$ Information Modelling Concept for Building Design, Estimation, Scheduling and Determination of Effective Variant. Technological and Economic Development of Economy 2006. 12(2): p. 91-98.

[25] Fischer, M. and J. Kunz, The Scope and Role of
Information Technology in Construction, in CIFE Technical Report. 2004, Center for Integrated Facility Engineering, Stanford University: San Francisco. p. 19.

[26] Creswell, J.W., Research Design: Qualitative, Quantitative, and Mixed Method Approaches. Second ed. 2002, London, New Delhi: SAGE Publications. 246.

[27] Morgan, D.L., Focus groups as qualitative research. 2nd ed. ed. 1997: Sage.

[28] Parker, A. and J. Tritter, Focus group method and methodology: current practice and recent debate. International Journal of Research and Method in Education, 2006. 29(1): p. 23-37. 